\title{
Clinicopathologic characteristics, therapeutic modalities and survival outcomes of plasmablastic lymphoma: A real-world study
}

\section{Type}

Research paper

\section{Keywords}

prognosis, SEER, Plasmablastic lymphoma, therapeutic modality

\begin{abstract}
Introduction

Plasmablastic lymphoma(PBL) $\square$ an extremely rare subtype of B-cell non-Hodgkin lymphoma, is characterized by aggressiveness, rapid progression and bleak prognosis. Neither standardized regimen nor consensus for PBL treatment has been established.
\end{abstract}

\begin{abstract}
Material and methods
We retrospectively analyzed the clinicopathologic characteristics, therapeutic modalities and survival outcomes of 418 patients registered in the Surveillance, Epidemiology, and End Results (SEER) database from 2008 to 2016 and 21 (19 treated) patients in our institution. Kaplan-Meier survival curves and log-rank test for overall survival and disease-specific survival were performed to compare each variable. Variables with statistical significance in the univariate Cox regression were incorporated into the multivariate model to determine the independent prognostic factors.
\end{abstract}

\section{Results}

In patient cohort from SEER, PBL has a striking male predilection. The median OS for all PBL patients was 17 months. The 1-year,3-year and 5-year OS rate were $54.4 \%, 40.4 \%$ and $37.2 \%$ respectively.Chemotherapy alone or chemotherapy combined with radiotherapy could significantly reduce the risk of death and extend the patients' survival, yielding HR of $0.209(95 \% \mathrm{Cl} 0.152-0.288)$ and $0.187(95 \% \mathrm{Cl} 0.089-0.394)$, respectively. Radiation alone seemed useless. All patients from our institution were HIV-negative. The main therapeutic regimens were $\mathrm{CHOP}$ or $\mathrm{CHOPE}, \mathrm{DA}-\mathrm{EPOCH}$, DHAP and ESHAP. Complete response was achieved in only 3 patients, while partial response in 10 patients. The median OS was 7 months. Fourteen patients later died of the disease progression.

\section{Conclusions}

Previous malignancy history, Ann Arbor stage and therapeutic modality were independent prognostic factors. Bortezomib combined with DA-EPOCH may serve as an effective regimen for PBL. The optimal therapeutic modality necessitates further exploration. 


\section{Clinicopathologic characteristics, therapeutic modalities and survival outcomes of plasmablastic lymphoma: A real-world study}

Running head: A real-world study of plasmablastic lymphoma

Yan-Hua Zheng ${ }^{1 \#}$, Kun Xie ${ }^{2 \#}$, Hong-Yuan Shen ${ }^{3}$, Zhuo Wan ${ }^{1}$, Shan Gao ${ }^{3}$, Wen-Rui Sun ${ }^{3}$, Guang-Xun $\mathrm{Gao}^{3}$, Li Liu ${ }^{1 *}$,Juan Feng ${ }^{3 *}$

Yan-Hua Zheng and Kun Xie contributed equally to this article as co-first authors

Yan-Hua Zheng's ORCID: https://orcid.org/0000-0002-7527-8248

1 Department of Hematology, Tangdu Hospital, Air Force Medical University, Xi'an, Shaanxi, China, 710038

2 Office of Drug Clinical Trial Institution, Xi'an Chest Hospital, Xi'an, Shaanxi, China, 710100

3 Department of Hematology, Xijing Hospital, Air Force Medical University, Xi'an, Shaanxi, China, 710032 


\section{Corresponding Author's information:}

Dr Juan Feng, Department of Hematology, Xijing Hospital, Air Force Medical University, 127 Chang'le West Road, 710032, Xi'an, Shaanxi,China.

E-mail: fengjuan2@,fmmu.edu.cn

Professor Li Liu, Department of Hematology, Tangdu Hospital, Air Force Medical University, No.1 Xin'si, Road, 710038, Xi'an, Shaanxi, China.

E-mail: heamatol@ffmmu.edu.cn 


\begin{abstract}
Introduction: Plasmablastic lymphoma(PBL), an extremely rare subtype of B-cell non-Hodgkin lymphoma(NHL), is characterized by aggressiveness, rapid progression and bleak prognosis. Neither standardized regimen nor consensus for PBL treatment has been established.
\end{abstract}

Methods: We retrospectively analyzed the clinicopathologic characteristics, therapeutic modalities and survival outcomes of 418 patients registered in the Surveillance, Epidemiology, and End Results (SEER) database from 2008 to 2016 and 21 (19 treated) patients in our institution. Kaplan-Meier survival curves and log-rank test for overall survival (OS) and disease-specific survival (DSS) were performed to compare each variable. Variables with statistical significance in the univariate Cox regression were incorporated into the multivariate Cox model to determine the independent prognostic factors.

Results: In patient cohort from the SEER, PBL has a striking male predilection. The median OS for all PBL patients was 17 months. The 1-year,3-year and 5-year OS rate were 54.4\%, $40.4 \%$ and $37.2 \%$ respectively. Patients who suffered from previous malignancy had a significant survival disadvantage compared to those without previous cancer. Patients with higher Ann Arbor stage at diagnosis were at higher risk of death than those with lower stage. Chemotherapy alone or chemotherapy combined with radiotherapy could significantly reduce the risk of death and extend the patients' survival, yielding HR of $0.209(95 \%$ CI $0.152-0.288$ ) 
and $0.187(95 \%$ CI 0.089-0.394), respectively. Radiation alone seemed useless. All patients from our institution were HIV-negative. The main therapeutic regimens were CHOP or CHOPE, DA-EPOCH, DHAP and ESHAP. Complete response (CR) was achieved in only 3 patients, while partial response (PR) in 10 patients. The median OS was 7 months. Fourteen patients later died of the disease progression.

Conclusions: Previous malignancy history, Ann Arbor stage and therapeutic modality were independent prognostic factors. Bortezomib combined with DA-EPOCH may serve as an effective regimen for PBL. The optimal therapeutic modality necessitates further exploration.

Keywords: Plasmablastic lymphoma, therapeutic modality, prognosis, SEER 


\section{Introduction}

Plasmablastic lymphoma (PBL) is an extremely rare and distinct subtype of B-cell non-Hodgkin lymphoma (NHL)[1, 2]. PBL exhibits mixed morphological characteristics of diffuse large B-cell lymphoma (DLBCL) and multiple myeloma (MM) with its highly aggressive attribute and plasmacytic differentiation[3]. The cell origin of PBL is considered the post-germinal center B-lymphocyte or plasmablast. Although PBL cells usually express classic biomarkers of plasmacytic differentiation (CD38,CD138 and MUM1) like MM and seldomly express B-lymphocyte differentiation markers (CD19, CD20, and PAX5), PBL bears a striking resemblance to DLBCL via genomic profiling[4]. It is often believed that PBL afflicts immunocompromised individuals, including those infected with human immunodeficiency virus(HIV), those receiving intense chemotherapy or radiotherapy for cancers, those undergoing organ or stem cell transplantation and those receiving immunorepressive drugs[5-7]. PBL was once regarded as a tumor that predominantly arose in patients with HIV-infection[8]. However, Castillo et al reported 71 HIV-negative PBL patients with unique clinicopathological characteristics markedly distinct from their HIV-positive counterparts[9].

PBL is notorious for resistance to chemotherapy, invasiveness and rapid progression. CHOP regimen (cyclophosphamide, doxorubicin, vincristine, and prednisone) serves as the first-line choice for the treatment of NHL. However, the National Comprehensive Cancer Network (NCCN) guidelines stipulate that standard CHOP seems 'inadequate and less intense' for PBL[10]. Despite the use of various regimens, the prognosis of PBL remains bleak. Owing 
to the rarity of PBL, previous publications mainly focus on clinical case report or case series with small sample-size. Little is known about this rare hematological malignancy. What's worse, neither standardized regimen nor consensus for PBL treatment has been established yet. The objective of our study is to further explore the clinical characteristic, prognostic factors and therapeutic modality of PBL on a larger scale. Patients in our study derived from the Surveillance, Epidemiology, and End Results (SEER) database and our institution. We also discussed the recent therapeutic approaches and advances in PBL.

\section{Methods and materials}

\subsection{Patient data from the SEER database}

\subsubsection{Patient selection}

Initially constructed by the National Cancer Institute of United States (US), the SEER database accounts for nearly $30 \%$ of the US population across 18 cancer registries and is completely available to the public via formal application. We obtained authorization to have access to the un-identified individual information. According to the International Classification of Disease for Oncology, 3rd edition (ICD-O-3), we retrieved the SEER database for PBL patients from 2008 to 2016 using the "9735/3: plasmablastic lymphoma" histology code in the "site and morphology ICD-O-3 histology/behavior, malignant" field. The patient data were downloaded by using SEER*Stat Software (Version 8.3.6, http://www.seer.cancer.gov/seerstat).

The patient data include age at diagnosis, gender, race, primary anatomical site, Ann 
Arbor stage, previous malignancy history, survival months, vital status, cause of death and the first round of treatment modalities (chemotherapy or not, radiation or not). However, the detailed HIV-infection status, immunohistochemical results, chemotherapy regimens, types of surgery, drug dosage and radiation dosage were not recorded in the SEER database. Patients without pathologically-confirmed diagnosis or sufficient follow-up information were excluded.

\subsubsection{Statistical analysis}

Overall survival (OS) was determined from the time of diagnosis to death from any cause or the last follow-up. Disease-specific survival (DSS) was calculated from diagnosis to the date of death caused by PBL. Kaplan-Meier curves and log-rank test for OS and DSS were conducted to compare each potential variable related to prognosis. Variables with $p$-value $<0.1$ in the univariate Cox regression model were incorporated into the multivariate Cox model to determine the independent prognostic factors, with hazard ratio (HR) $>1$ indicating adverse factors. All tests were two-sided, with $\mathrm{p}$-value $<0.05$ regarded statistically significant. All statistical analysis were performed with SPSS Software (Version 26.0, IBM Corp., USA).

\subsection{Patient group from our institution}

We then retrospectively identified $21 \mathrm{PBL}$ patients in our institution between Aug 2009 and Aug 2018. In accordance with the 2008 WHO classification of tumors of hematopoietic and lymphoid tissues, the pathological diagnosis was made through 
hematoxylin-eosin staining and immunophenotyping results.

Relevant clinical information of 21 PBL patients included age at diagnosis, gender, HIV infectious status, Eastern Cooperative Oncology Group performance status (ECOG-PS), Ann-Arbor stage, international prognostic index (IPI), primary tumor locations, immunochemistry results, specific therapeutic regimen, the best response to therapy and the final survival outcomes. Immunohistochemical studies were conducted on formalin-fixed, paraffin-embedded tissue sections by utilizing the antibodies including CD138, CD38, CD10, CD20, CD79, PAX5, MUM1, CD30, CD56, BCL6, CD5,CD3, CD45 and Ki67. In situ hybridization (ISH) for EB virus-encoded small RNA (EBER) was also detected by employing a fluorescein-labeled peptide nucleic acid probe on the tissue sections.

Given the rarity of PBL and the small sample size from our institution, we consider it unreasonable to conduct log-rank test or COX regression analysis. Therefore, we only plotted an OS curve to demonstrate the patient survival outcomes.

\section{Results}

\subsection{Patients from the SEER population registries}

After rigorous identification, a total of 418 eligible patients were ultimately enrolled in our study. The flow diagram of selection process was revealed in Figure1.The demographic and clinical characteristics of PBL patients were summarized in Table1. The median age at diagnosis was 56 years-old. PBL has a striking gender predilection for males with the ratio of

male to female patient being 3.5:1. Patients with B symptoms accounted for $23.68 \%$. Nearly 
$18.7 \%$ of the patients had a previous history of other malignancies. However, the SEER database did not record the information on the HIV infection status. Only $6 \%$ of the patients received both chemotherapy and radiation at initial diagnosis, while $66 \%$ received chemotherapy alone and $26.8 \%$ of patients were untreated.

The distribution of primary anatomical sites was revealed in Table 2. Of all the patients, 185 cases $(44.26 \%)$ were detected within the lymph nodes and $233(55.74 \%)$ cases suffered from extranodal infiltration. The most frequently-involved extranodal site was gastrointestinal tract $(20.10 \%)$, followed by nasal cavity/paranasal sinuses $(11.72 \%)$ and oral cavity, mouth and tongue $(5.50 \%)$.

Some patients died promptly after initial diagnosis due to the highly aggressiveness and rapid progression of PLB, therefore the follow-up time is very short. While other patients survived several years after diagnosis. The follow-up time of each individual patient varied considerably..As was revealed in the Kaplan-Meier curves of OS(Figure 2A) and DSS(Figure 2B), the median OS for all PBL patients was 17 months (95\%CI 10.3-23.7). The 1-year,3-year and 5-year OS rate were $54.4 \%, 40.4 \%$ and $37.2 \%$ respectively. The median DSS was not reached, and the 1-year,3-year and 5-year DSS rate were 69\%, 58.6\% and 55\%, respectively.

In the univariate assessment, marital status( $\mathrm{p}=0.015)$,previous malignancy history $(p=0.003)$, primary $\operatorname{site}(p=0.009)$, Ann Arbor $\operatorname{stage}(p=0.001)$, therapeutic modality $(\mathrm{p}<0.001)$ are the possible predictive factors of OS (Table 3). Age, gender and race could not influence PBL prognosis. The predictors of DSS were similar to those of OS (Table 3). Kaplan-Meier survival curves gave a vivid description of the association between various 
factors and OS(Figure 3) and DSS(Figure 4) of PLB patients. As revealed in Table 4, multivariate analysis verified that previous malignancy history, Ann Arbor stage and therapeutic modality were independent prognostic factors. Patients who suffered from previous malignancy had a significant survival disadvantage $[\mathrm{HR}=1.444,95 \% \mathrm{CI}$ (1.037-2.001)] compared to those without previous cancer. Patients with higher Ann Arbor stage at diagnosis were at higher risk of death than those with lower stage. In terms of therapeutic modalities, chemotherapy alone or chemotherapy combined with radiotherapy could significantly reduce the risk of death and extend the patients' survival, yielding HR of $0.209(95 \%$ CI $0.152-0.288, \mathrm{p}<0.001)$ and $0.187(95 \%$ CI $0.089-0.394, \mathrm{p}<0.001)$, respectively. However, radiation alone without chemotherapy seemed useless.

\subsection{Patients from our institution}

We enrolled altogether 21 patients including 12 males and 9 females. The median age at diagnosis was 52 years-old. Clinical features and immunophenotypical results of patients from our institution were demonstrated in Table5. All patients were HIV-negative and were not in immunocompromised status. Tumor arose extranodally in 16 cases(76.2\%).Plasma cell markers including CD38, CD138, and MUM1, were universally detected positivity $(81 \%, 90 \%$ and $85.7 \%$,respectively), while CD20 and PAX5 were detected negativity in most cases(90.5\% and $86.7 \%$,respectively). The proliferation index Ki-67 was commonly high, ranging from 40\% to $95 \%$ with 16 cases $>80 \%$. EBER was detected positivity in 5 out of 17 cases( $29.4 \%)$.

Detailed information on therapeutic regimen and survival outcomes was summarized 
in Table 6. The Kaplan-Meier plot for the whole group revealed that median OS was 7 months (Figure 5). CHOP regimen (cyclophosphamide, doxorubicin, vincristine, and prednisone) or CHOPE regimen (CHOP+etoposide) were selected as the first-line therapy for most patients.

\section{DA-EPOCH}

(dose-adjusted

etoposide,adriamycin,vincristine,cyclophosphamide,prednisone),DHAP(cisplatin, high-dose cytarabine,dexamethasone),

DICE(cisplatin,ifosfamide,etoposide,dexamethasone),ESHAP(etoposide,methylprednisolone, high-dose cytarabine,cisplatin), GDP(gemcitabine,cisplatin,dexamethasone) and HyperCVAD/high-dose

MTX/Ara-C(hyper-fractionated cyclophosphamide,vincristine,doxorubicin,dexamethasone alternating with methotrexate and cytarabine) were reasonable options. Regimens for the treatment of $\mathrm{MM}$ such as PAD(bortezomib,adriamycin, dexamethasone),PCD(bortezomib,cyclophosphamide, dexametha sone), TAD(thalidomide, adriamycin,dexamethasone), MPT(melphalan+prednisone+thalidomide) were also administered. Only one patient who received autologous stem cell transplantation (ASCT) with thalidomide maintainance is still alive by the end of our study. Complete response(CR) was achieved in only 3 patients who are still alive at the study endpoint. Partial response(PR) was obtained in 10 patients. Efficacy was limited and transient in most patients. Fourteen patients later died of the disease progression.

\section{Discussion}


Initially described in the oral cavity of HIV-infected patients in 1997, PBL is characterized by male predominance, predilection for extranodal involvement and higher incidence among immunocompromised patients[8]. Highly active antiretroviral therapy (HAART) is oriented to kill HIV, which mainly includes stavudine in combination with lamivudine and nevirapine, zidovudine in combination with lamivudine and efavirenz, and emtricitabine in combination with tenofovir and kaletra[11, 12]. Some case reports depicted the spontaneous regression of HIV-related PBL after use of HAART. However, sustained CR could not be achieved and patients were confronted with early relapse[13, 14]. A study from LYmphoma Study Association (LYSA) Group also verified that HAART alone without chemotherapy could not achieve sustained CR[15].The administration of HAART combined with chemotherapy is preferably recommended in HIV-positive patients.

With the increased understanding of PBL, we have come to realize that PBL also emanates in HIV-negative or other immunocompetent patients. All patients from our institution were HIV-negative and previously-immunocompetent with a normal level of CD4+T cell counts. HIV-positive and HIV-negative PBL are two strikingly distinct subentities with different clinicopathological characteristics. HIV-negative patients bore bleaker prognosis, worse response to chemotherapy and shorter OS than HIV-positive patients $[9,15,16]$. Some cases with oral cavity involvement are correlated with EB virus(EBV). The criteria for PBL diagnosis have varied over time. Some researches rigorously defined coexistence of lesion in the oral cavity and presence of HIV or EBV. But now classification of PBL has been defined in a broader sense, in which morphology and 
immunophenotype correspond with B immunoblasts or plasma cells with EBV-negativity and extranodal involvement in other parts of the body[17].

We should make reasonable differential diagnosis to tell apart anaplastic lymphoma kinase-postive large B-cell lymphoma(ALK+ LBCL), primary effusion lymphoma(PEL), Epstein-Barr virus-positive DLBCL, human herpes virus 8-positive DLBCL, intravascular large B-cell lymphoma(IVLBCL) and other specific variants of DLBCL[2, 18].PBL is not always associated with EBV positivity.PBL exhibits a 'terminal B-cell differentiation' phenotypical feature with upregulation of plasma cell markers(CD138, CD38) and downregulation of B-cell markers. ALK-positive large B-cell lymphoma (ALK+ LBCL) exhibits immunoblast-like or plasmablast-like features with prominent overexpression of ALK protein due to ALK translocation and prevalent positivity of plasma cell-associated markers[19, 20].

There has been no standard therapeutic regimen for PBL.Arora's study reported that median OS of the entire cohort was 15.9 months. The median OS for treated and untreated patients was 17.9 months and 0.9 months, respectively[21].Despite the fact that the most commonly-used regimen is CHOP or CHOP-like at present, the NCCN guidelines state that CHOP is 'inadequate and inefficient' and propose more intensive regimens including DA-EPOCH, HyperCVAD and CODOX-M/IVAC (cyclophosphamide, vincristine, doxorubicin,methotrexate/ifosfamide,etoposide,cytarabine)[10]. The MD Anderson center reported patients who underwent $\mathrm{CHOP}$ regimen tended to enjoy better OS compared with those who underwent hyper-CVAD regimen (hyperfractionated cyclophosphamide, 
vincristine, doxorubicin, and dexamethasone), which can be explained by the fact that hyper-CVAD is much intense and possesses more "toxicity" than the CHOP regimen[22].The efficacy of adding rituximab (a kind of anti-CD20 monoclonal antibody) to conventional chemotherapy remains obscure. We speculate that the addition of rituximab is unlikely to achieve clinical benefit in that PBL cells scarcely express CD20 antigen. Several studies have shown that EPOCH displayed better efficacy and survival outcomes than CHOP, especially in highly-aggressive B-cell NHL[23, 24]. Castillo et al reported 3 PBL patients achieved a durable $\mathrm{CR}$ to $\mathrm{V}$-DAEPOCH(bortezomib in combination with dose-adjusted etoposide, prednisone, vincristine, cyclophosphamide, and doxorubicin) with OS of 12,18,24months respectively[25].Dittus et al reported V-DAEPOCH regimen was efficacious and well-tolerated in $8 \mathrm{PBL}$ patients, achieving CR rate of $100 \%$ and 2 -year OS rate of 50\%[26].In 2018, Castillo et al reported that among 16 patients who received V-DAEPOCH regimen (range 4-6 cycles), CR was observed in 15 patients and PR in 1 patient. The 5-year OS rate was $65 \%$. Of the 5 dead patients, 3 died of PBL progression and 2 died of infection[27]. Infusional EPOCH regimen resulted in long-lasting remission in 13 patients with extranodal involvement[28].The above-mentioned indicates that V-DAEPOCH is an effective and frontline therapeutic regimen for PBL.

Lenalidomide is a kind of immunomodulatory agent, which is widely used for MM treatment. RCD regimen (lenalidomide in combination with cyclophosphamide and dexamethasone) was reported to successfully treat a stage IE HIV-negative PBL patient, achieving an at least 24 months' durable CR[29]. Similarly, an HIV-positive PBL was 
effectively treated with lenalidomide combined with $\mathrm{CHOP}[30]$.

A case-control study suggested that there was no significant difference in non-relapse mortality,2-year disease-free survival and OS between HIV-positive and HIV-negative NHL patients who received ASCT. That is to say, HIV status does not influence the long-term outcome of ASCT for NHL[31]. ASCT during first CR after intensive induction therapy is a feasible solution to improve the PBL outcome[32].Infusional EPOCH with subsequent consolidation ASCT in the eligible patients were recommended for treating HIV-associated PBL[33]. The European Society for Blood and Marrow Transplantation registry reported 24 PBL patients who underwent ASCT. Those who were autografted in CR displayed a significantly decreased relapse risk and overall mortality risk[34].ASCT warrants to be further investigated as first-line consolidation and salvage therapy for both HIV-positive and negative PBL patients especially in the absence of effective therapeutic options[35]. Nishi et al reported that an HIV-negative woman with chemotherapy-refractory PBL had disease-free survival of more than 18 months after umbilical cord stem cell transplantation(UBSCT)[36].

PRDM1 gene mutation was frequently found in PBL and greatly augmented the oncogenicity of MYC gene to enhance the proliferative activity by inducing MYC translocation or amplification. In a sense, PRDM1 mutations can be genetically regarded as a second hit in PBL and may become a therapeutic target in the future[37].A recent study found that CD30 were pronounced expressed in PBL tissue and will become a target with the potential use of brentuximab vedotin[38].

There existed several inevitable defects in our study mainly owing to the inherent 
drawbacks of SEER database. Firstly, the SEER is a population-based registry and does not record some important individual information, such as ECOG-PS, IPI, tumor size,immunohistochemistry results, FISH results, cytogenetic abnormalities, virus infection status and lactate dehydrogenase (LDH). Secondly, information concerning comorbidities, disease progression and relapse were not documented. Thirdly, the specific drug dosage and radiation dose were neither recorded in the SEER database. Whether PBL patients received ASCT was unknown from the SEER. What's more, dates of information retrieval spanned a long period of time, which witnessed the variations in diagnostic criteria and the advancement of therapeutic approaches. The high heterogeneity of PLB cannot be neglected as well.Lastly, research on patients from our institution were small sample-sized due to the scarcity of PBL.

In conclusion, PBL is an extremely rare and aggressive entity of B-cell NHL. Despite being initially reported in HIV-infected patients, PBL has also been identified in other immunocompetent patients. PBL has a male predilection. The cohort from SEER database revealed that previous malignancy history, Ann Arbor stage, therapeutic modality were independent prognostic factors. Bortezomib combined with DA-EPOCH may serve as an effective and frontline therapeutic regimen for PBL. Prospective clinical trials should also be further conducted to explore the efficacy and safety of novel agents including chimeric antigen receptor $\mathrm{T}$ cell(CAR-T) therapy, immune checkpoint inhibitors and other monoclonal antibodies for the treatment of PBL. 


\section{Funding}

This study was funded by the National Natural Science Foundation of China (NSFC 31572344 to Professor Li Liu, NSFC 81970190 to Professor Gao).

\section{Conflict of Interest Statement}

All authors declare no conflict of interest.

\section{Data Availability Statement}

All original data throughout our manuscript are available upon request by communicating with corresponding author.

\section{Ethic statement}

Before commencing this study, we obtained informed consent from patients or their next of kins(if the patients were dead) and official ethical approval from institutional review board of Fourth Military Medical University. The SEER database provides un-identified individual information and is totally available to the public after formal application. We received permission from the SEER program funded by the National Cancer Institute of United States to gain access to the patient information. 


\section{References}

\section{References}

1. Swerdlow SH, Campo E, Pileri SA, et al. The 2016 revision of the World Health Organization classification of lymphoid neoplasms. Blood 2016; 127: 2375-90.

2. Grimm KE, O'Malley DP. Aggressive B cell lymphomas in the 2017 revised WHO classification of tumors of hematopoietic and lymphoid tissues. Ann Diagn Pathol 2019; 38: 6-10.

3. Montes-Moreno S, Montalbán C, Piris MA. Large B-cell lymphomas with plasmablastic differentiation: a biological and therapeutic challenge. Leuk Lymphoma 2012; 53: 185-94.

4. Chang CC, Zhou X, Taylor JJ, et al. Genomic profiling of plasmablastic lymphoma using array comparative genomic hybridization $(\mathrm{aCGH})$ : revealing significant overlapping genomic lesions with diffuse large B-cell lymphoma. J Hematol Oncol 2009; 2: 47.

5. Morscio J, Dierickx D, Nijs J, et al. Clinicopathologic comparison of plasmablastic lymphoma in HIV-positive, immunocompetent, and posttransplant patients: single-center series of 25 cases and meta-analysis of 277 reported cases. Am J Surg Pathol 2014; 38: 875-86.

6. Castillo J, Pantanowitz L, Dezube BJ. HIV-associated plasmablastic lymphoma: lessons learned from 112 published cases. Am J Hematol 2008; 83: 804-9.

7. Liu M, Liu B, Liu B, Wang Q, Ding L, Xia C, Dong L. Human immunodeficiency virus-negative plasmablastic lymphoma: a comprehensive analysis of 114 cases. Oncol Rep 2015; 33: 1615-20.

8. Delecluse HJ, Anagnostopoulos I, Dallenbach F, et al. Plasmablastic lymphomas of the oral cavity: a new entity associated with the human immunodeficiency virus infection. Blood 1997; 89: 1413-20.

9. Castillo JJ, Winer ES, Stachurski D, et al. Clinical and pathological differences between human immunodeficiency virus-positive and human immunodeficiency virus-negative patients with plasmablastic lymphoma. Leuk Lymphoma 2010; 51: 2047-53.

10. Zelenetz AD, Gordon LI, Abramson JS, et al. NCCN Guidelines Insights: B-Cell Lymphomas, Version 3.2019. J Natl Compr Canc Netw 2019; 17: 650-61.

11. Koizumi Y, Uehira T, Ota Y, et al. Clinical and pathological aspects of human immunodeficiency virus-associated plasmablastic lymphoma: analysis of 24 cases. Int J Hematol 2016; 104: 669-81.

12. Wang D, Zheng Y, Zeng D, Yang Y, Zhang X, Feng Y, Lu H. Clinicopathologic characteristics of HIV/AIDS-related plasmablastic lymphoma. Int J STD AIDS 2017; 28: 380-8. 
13. Nasta SD, Carrum GM, Shahab I, Hanania NA, Udden MM. Regression of a plasmablastic lymphoma in a patient with HIV on highly active antiretroviral therapy. Leuk Lymphoma 2002; 43: 423-6.

14. Armstrong R, Bradrick J, Liu YC. Spontaneous regression of an HIV-associated plasmablastic lymphoma in the oral cavity: a case report. J Oral Maxillofac Surg 2007; 65: 1361-4.

15. Tchernonog E, Faurie P, Coppo P, et al. Clinical characteristics and prognostic factors of plasmablastic lymphoma patients: analysis of 135 patients from the LYSA group. Ann Oncol 2017; 28: 843-8.

16. Liu JJ, Zhang L, Ayala E, et al. Human immunodeficiency virus (HIV)-negative plasmablastic lymphoma: a single institutional experience and literature review. Leuk Res 2011; 35: 1571-7.

17. Cesarman E. Gammaherpesviruses and lymphoproliferative disorders. Annu Rev Pathol 2014; 9: 349-72.

18. Sukswai N, Lyapichev K, Khoury JD, Medeiros LJ. Diffuse large B-cell lymphoma variants: an update. Pathology 2020; 52: 53-67.

19. Pan Z, Hu S, Li M, et al. ALK-positive Large B-cell Lymphoma: A Clinicopathologic Study of 26 Cases With Review of Additional 108 Cases in the Literature. Am J Surg Pathol 2017; 41: 25-38.

20. Qunaj L, Castillo JJ, Olszewski AJ. Survival of patients with CD20-negative variants of large B-cell lymphoma: an analysis of the National Cancer Data Base. Leuk Lymphoma 2018; 59: 1375-83.

21. Arora N, Eule C, Gupta A, Li HC, Sadeghi N. Clinicopathologic features, management, and outcomes of plasmablastic lymphoma: A 10-year experience. Am J Hematol 2019; 94: E127-127E129.

22. Loghavi S, Alayed K, Aladily TN, et al. Stage, age, and EBV status impact outcomes of plasmablastic lymphoma patients: a clinicopathologic analysis of 61 patients. J Hematol Oncol 2015; 8: 65.

23. Barta SK, Lee JY, Kaplan LD, Noy A, Sparano JA. Pooled analysis of AIDS malignancy consortium trials evaluating rituximab plus CHOP or infusional EPOCH chemotherapy in HIV-associated non-Hodgkin lymphoma. Cancer 2012; 118: 3977-83.

24. Petrich AM, Gandhi M, Jovanovic B, et al. Impact of induction regimen and stem cell transplantation on outcomes in double-hit lymphoma: a multicenter retrospective analysis. Blood 2014; 124: 2354-61.

25. Castillo JJ, Reagan JL, Sikov WM, Winer ES. Bortezomib in combination with infusional dose-adjusted EPOCH for the treatment of plasmablastic lymphoma. Br J Haematol 2015; 169: 352-5.

26. Dittus C, Grover N, Ellsworth S, Tan X, Park SI. Bortezomib in combination with dose-adjusted EPOCH (etoposide, prednisone, vincristine, cyclophosphamide, and doxorubicin) induces long-term survival in patients with plasmablastic lymphoma: a retrospective analysis. Leuk Lymphoma 2018; 59: 2121-7.

27. Castillo JJ, Guerrero-Garcia T, Baldini F, et al. Bortezomib plus EPOCH is effective as frontline treatment in patients with plasmablastic lymphoma. Br J Haematol 2019; 184: 679-82.

28. Jayachandran PK, Rajan AK, Karunakaran P, et al. Plasmablastic lymphoma - single centre experience with infusional EPOCH chemotherapy. Leuk Res 2020; 95: 106391.

29. Schmit JM, DeLaune J, Norkin M, Grosbach A. A Case of Plasmablastic Lymphoma Achieving Complete Response and Durable Remission after Lenalidomide-Based Therapy. Oncol Res Treat 2017; 40: 46-8.

30. Yanamandra U, Sahu KK, Jain N, Prakash G, Saikia U, Malhotra P. Plasmablastic lymphoma: successful management with CHOP and lenalidomide in resource constraint settings. Ann Hematol 2016; 95: 1715-7.

31. Krishnan A, Palmer JM, Zaia JA, Tsai NC, Alvarnas J, Forman SJ. HIV status does not affect the outcome of autologous stem cell transplantation (ASCT) for non-Hodgkin lymphoma (NHL). Biol Blood Marrow Transplant 2010; 16: 1302-8.

32. Al-Malki MM, Castillo JJ, Sloan JM, Re A. Hematopoietic cell transplantation for plasmablastic lymphoma: a review. Biol Blood Marrow Transplant 2014; 20: 1877-84.

33. Dunleavy K, Wilson WH. How I treat HIV-associated lymphoma. Blood 2012; 119: 3245-55. 
34. Cattaneo C, Finel H, McQuaker G, Vandenberghe E, Rossi G, Dreger P. Autologous hematopoietic stem cell transplantation for plasmablastic lymphoma: the European Society for Blood and Marrow Transplantation experience. Biol Blood Marrow Transplant 2015; 21: 1146-7.

35. Balsalobre P, Díez-Martín JL, Re A, et al. Autologous stem-cell transplantation in patients with HIV-related lymphoma. J Clin Oncol 2009; 27: 2192-8.

36. Nishi K, Mitani S, Hatanaka K, Imada K. Successful cord blood transplantation for an HIV-negative patient with refractory plasmablastic lymphoma. Ann Hematol 2017; 96: 1057-8.

37. Montes-Moreno S, Martinez-Magunacelaya N, Zecchini-Barrese T, et al. Plasmablastic lymphoma phenotype is determined by genetic alterations in MYC and PRDM1. Mod Pathol 2017; 30: 85-94.

38. Witte HM, Hertel N, Merz H, et al. Clinicopathological characteristics and MYC status determine treatment outcome in plasmablastic lymphoma: a multi-center study of 76 consecutive patients. Blood Cancer J 2020; 10: 63.

\section{Table Title (Full tables are uploaded in EXCEL file)}

Table1. Demographic and clinical characteristics of 418 patients from SEER database

Table2. The primary anatomic sites distribution of plasmablastic lymphoma

Table3. Univariate Cox regression analysis of overall survival and disease-specific survival

Table4. Multivariate Cox regression analysis of overall survival and disease-specific survival

Table5. Clinical features and immunophenotypical results of 21 patients with plasmablastic lymphoma in our institution

Table6. Therapeutic regimen and survival outcomes of 19 treated patients with plasmablastic lymphoma in our institution

\section{Figure Legend}

Figure1. The flow chart of the selection process for the eligible patient cohort.

Figure2. Kaplan-Meier curves of the whole eligible cohort: (A) Overall survival; (B) Disease-specific survival

Figure3. Kaplan-Meier estimate of overall survival by subgroup analysis: (A) Age; (B) Marital status; (C) Previous malignancy history; (D) Primary site; (E) Ann Arbor stage; 
(F)Therapeutic modality.

Figure4. Kaplan-Meier estimate of disease-specific survival by subgroup analysis: (A) Marital status; (B)Primary site; (C)Ann Arbor stage;(D)Therapeutic modality.

Figure5. Overall survival of 19 plasmablastic lymphoma patients treated in our institution. 
Table1.Demographic and clinical characteristics of 418 patients from SEER database

\begin{tabular}{|c|c|c|c|}
\hline Characteristics & & Number & Percentage \\
\hline \multirow[t]{6}{*}{ Age (median, years) } & & $56(9-95)$ & \\
\hline & $0-20$ & 3 & $0,72 \%$ \\
\hline & $20-40$ & 75 & $17,94 \%$ \\
\hline & $40-60$ & 175 & $41,87 \%$ \\
\hline & $60-80$ & 134 & $32,06 \%$ \\
\hline & $>80$ & 31 & $7,42 \%$ \\
\hline \multicolumn{4}{|l|}{ Gender } \\
\hline & Male & 325 & $77,75 \%$ \\
\hline & Female & 93 & $22,25 \%$ \\
\hline \multicolumn{4}{|l|}{ Race } \\
\hline & White & 323 & $77,27 \%$ \\
\hline & Black & 66 & $15,79 \%$ \\
\hline & Others & 29 & $6,94 \%$ \\
\hline \multicolumn{4}{|l|}{ Marital status } \\
\hline & Married & 166 & $39,71 \%$ \\
\hline & Single & 172 & $41,15 \%$ \\
\hline & Divorced/separated/widowed & 56 & $13,40 \%$ \\
\hline & Unknown & 24 & $5,74 \%$ \\
\hline \multicolumn{4}{|l|}{ Primary site } \\
\hline & Nodal & 185 & $44,26 \%$ \\
\hline & Extranodal & 233 & $55,74 \%$ \\
\hline \multicolumn{4}{|l|}{ Ann Arbor stage } \\
\hline & I & 93 & $22,25 \%$ \\
\hline & II & 66 & $15,79 \%$ \\
\hline & III & 43 & $10,29 \%$ \\
\hline & IV & 153 & $36,60 \%$ \\
\hline & Unknown & 63 & $15,07 \%$ \\
\hline \multicolumn{4}{|l|}{ B symptoms } \\
\hline & Yes & 99 & $23,68 \%$ \\
\hline & No & 197 & $47,13 \%$ \\
\hline & Unknown & 122 & $29,19 \%$ \\
\hline \multicolumn{4}{|c|}{ Previous malignancy history } \\
\hline & Yes & 78 & $18,66 \%$ \\
\hline & No & 340 & $81,34 \%$ \\
\hline \multicolumn{4}{|l|}{ Therapeutic modality } \\
\hline & Chemotherapy alone & 276 & $66,03 \%$ \\
\hline & Radiation alone & 5 & $1,20 \%$ \\
\hline
\end{tabular}


Table 2. The primary anatomic sites distribution of plasmablastic lymphoma

\begin{tabular}{llcc}
\hline & Primary anatomic sites & Number & Percentage \\
\hline \multirow{2}{*}{$\begin{array}{l}\text { Nodal } \\
\text { Extranodal }\end{array}$} & $\mathbf{1 8 5}$ & $44,26 \%$ \\
& Oral cavity,mouth,tongue & $\mathbf{2 3 3}$ & $55,74 \%$ \\
& Nasal cavity and sinus & 23 & $5,50 \%$ \\
& Gastrointestinal tract & 49 & $11,72 \%$ \\
Stomach and esophagus & 84 & $20,10 \%$ \\
$\quad$ Small intestine & 22 & $5,26 \%$ \\
Colon,retum,anus,cecum & 11 & $2,63 \%$ \\
& 51 & $12,20 \%$ \\
& Skin and connective tissue & 19 & $4,55 \%$ \\
& Lung and pleura & 8 & $1,91 \%$ \\
& Urogenital system & 11 & $2,63 \%$ \\
& Bone & 7 & $1,67 \%$ \\
Central nervous system & 9 & $2,15 \%$ \\
Bone marrow & 11 & $2,63 \%$ \\
Other organs & 12 & $2,87 \%$ \\
\hline
\end{tabular}


Table3. Univariate Cox regression analysis of overall survival and disease-specific survival

\begin{tabular}{|c|c|c|c|c|c|c|}
\hline \multirow[b]{2}{*}{ Variables } & \multicolumn{3}{|c|}{ Overall survival } & \multicolumn{3}{|c|}{ Disease-specific survival } \\
\hline & $\begin{array}{c}\text { Median } \\
\text { survival } \\
(95 \% \mathrm{CI}) \\
\end{array}$ & $\begin{array}{l}\text { Harzard ratio } \\
(95 \% \mathrm{CI})\end{array}$ & p-Value & $\begin{array}{c}\text { Median } \\
\text { survival } \\
(95 \% \mathrm{CI})\end{array}$ & $\begin{array}{c}\text { Harzard ratio } \\
(95 \% \mathrm{CI})\end{array}$ & p-Value \\
\hline \multicolumn{7}{|l|}{$\overline{\text { Age }}$} \\
\hline$<60 \mathrm{y}$ & $22(12.7-31.3)$ & Reference & 0,052 & NA & Reference & 0,718 \\
\hline$>60 y$ & $11(4.7-17.3)$ & $\begin{array}{l}\text { 1.J (U.YYO- } \\
1 \text { (nE) }\end{array}$ & & NA & $0.937(0.66-1.332)$ & \\
\hline \multicolumn{7}{|l|}{ Sex } \\
\hline Male & $18(9.6-26.4)$ & Reference & & NA & Reference & \\
\hline Female & $13(1.6-24.4)$ & $1.13(0.83-1.54)$ & 0,43 & NA & $0.721(0.46-1.13)$ & 0,153 \\
\hline \multirow[t]{4}{*}{ Race } & & & 0,364 & & & 0,938 \\
\hline & $30(17.5-\mathrm{NA})$ & Reference & & NA & Reference & \\
\hline & $17(7.3-41.1)$ & $1.13(0.80-1.60)$ & 0,493 & NA & $1.229(0.799-1.89)$ & 0,349 \\
\hline & $21.8(4-55.2)$ & $1.32(0.80-2.18)$ & 0,283 & NA & $\begin{array}{c}0.879(0.409- \\
1.892)\end{array}$ & 0,742 \\
\hline Marital status & & & 0,015 & & & $\mathbf{0 , 0 3 9}$ \\
\hline Married & $35(8.2-61.8)$ & Reference & & NA & Reference & \\
\hline Single & $21(9.8-32.2)$ & $\begin{array}{c}1.192(0.879- \\
1.615)\end{array}$ & 0,258 & NA & $\begin{array}{c}1.566(1.055- \\
2.325)\end{array}$ & 0,026 \\
\hline Divorced/separated/widowed & $7(4.4-9.6)$ & $\begin{array}{c}1.815(1.232- \\
2.674)\end{array}$ & 0,003 & 13 & $\begin{array}{c}2.094(1.261- \\
3.478)\end{array}$ & 0,004 \\
\hline \multicolumn{7}{|l|}{ Previous malignancy history } \\
\hline No & $21(11.1-30.9)$ & Reference & & NA & Reference & \\
\hline Yes & $8(3.8-12.2)$ & $1.61(1.18-2.20)$ & $\mathbf{0 , 0 0 3}$ & NA & $0.04(0.006-0.285)$ & 0,001 \\
\hline \multicolumn{7}{|l|}{ Primary site } \\
\hline Nodal & $11(6.5-15.5)$ & Reference & & NA & Reference & \\
\hline Extranodal & $30(18.5-41.5)$ & $0.7(0.54-0.91)$ & 0,009 & NA & $0.68(0.485-0.953)$ & 0,025 \\
\hline \multirow[t]{4}{*}{ Ann Arbor stage } & & & $\mathbf{0 , 0 0 1}$ & & & 0,044 \\
\hline & NA & Reference & & NA & Reference & \\
\hline & $16(6.2-25.8)$ & $1.69(1.087-2.627)$ & 0,02 & NA & $1.86(1.048-3.299)$ & 0,034 \\
\hline & $11(3.6-18.4)$ & $\begin{array}{c}1.738(1.064- \\
2.840)\end{array}$ & 0,027 & 55 & $\begin{array}{c}1.705(0.884- \\
3.288)\end{array}$ & 0,111 \\
\hline
\end{tabular}




\begin{tabular}{|c|c|c|c|c|c|c|}
\hline IV & $8(2.8-13.2)$ & $\begin{array}{c}2.005(1.384- \\
2.903)\end{array}$ & $<0.001$ & 30 & $\begin{array}{c}2.245(1.382- \\
3.647)\end{array}$ & $<0.001$ \\
\hline \multicolumn{7}{|l|}{ B symptoms } \\
\hline No & $25(11.6-38.4)$ & Reference & & NA & Reference & \\
\hline \multirow[b]{2}{*}{ Therapeutic modality } & $15(6.0-24.0)$ & $\begin{array}{c}1.256(0.912- \\
1.730)\end{array}$ & 0,163 & NA & $\begin{array}{c}1.279(0.857- \\
1.909)\end{array}$ & 0,229 \\
\hline & & & $<0.001$ & & & $<0.001$ \\
\hline No treatment & $2(1.2-2.8)$ & Reference & & $6(4.1-7.9)$ & Reference & \\
\hline Chemotherapy alone & 30 & $0.277(0.21-0.367)$ & $<0.001$ & NA & $\begin{array}{c}0.282(0.197- \\
0.403)\end{array}$ & $<0.001$ \\
\hline Radiation alone & $18(0-39.5)$ & $\begin{array}{c}0.461(0.169- \\
1.259)\end{array}$ & 0,131 & NA & $\begin{array}{c}0.191(0.026- \\
1.386)\end{array}$ & 0,102 \\
\hline Combined therapy & NA & $\begin{array}{c}0.151(0.073- \\
0.312) \\
\end{array}$ & $<0.001$ & NA & $0.19(0.081-0.444)$ & $<0.001$ \\
\hline
\end{tabular}




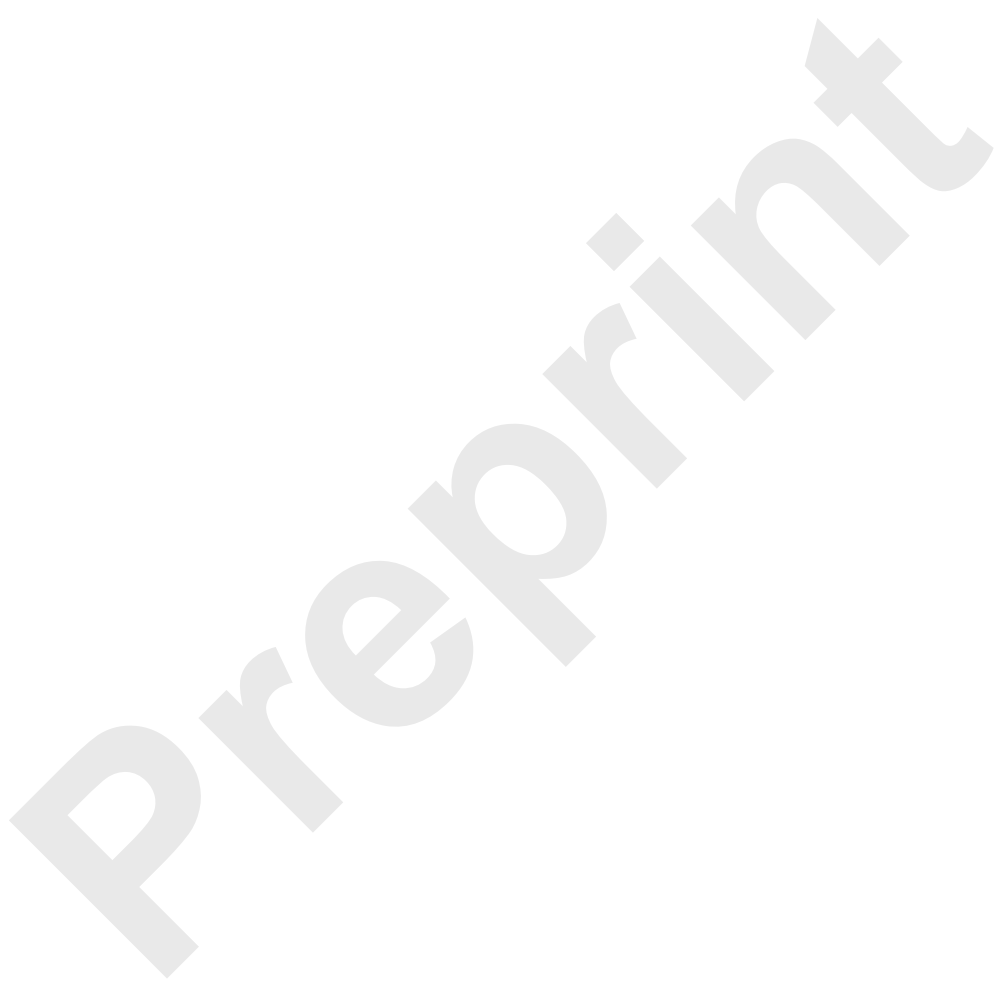


Table4.Multivariate Cox regression analysis of overall survival and disease-specific survival

\begin{tabular}{|c|c|c|c|c|}
\hline \multirow{2}{*}{ Variables } & \multicolumn{2}{|l|}{ Overall survival } & \multicolumn{2}{|c|}{ Disease-specific survival } \\
\hline & Hazard ratio $(95 \% \mathrm{CI})$ & p-Value & Hazard ratio $(95 \% \mathrm{CI})$ & p-Value \\
\hline \multicolumn{5}{|l|}{$\overline{\text { Marital status }}$} \\
\hline Married & Reference & & Reference & \\
\hline Single & $1.227(0.875-1.720)$ & 0,236 & $1.513(1.003-2.282)$ & 0,048 \\
\hline Divorced/separated/widowed & $1.477(0.987-2.209)$ & 0,058 & $2.107(1.253-3.544)$ & 0,005 \\
\hline \multicolumn{5}{|l|}{ Previous malignancy history } \\
\hline No & Reference & & l & \\
\hline Yes & $1.444(1.037-2.011)$ & 0,029 & l & \\
\hline \multicolumn{5}{|l|}{ Primary site } \\
\hline Nodal & Reference & & Reference & \\
\hline Extranodal & $0.798(0.598-1.065)$ & 0,126 & $0.702(0.483-1.019)$ & 0,063 \\
\hline \multicolumn{5}{|l|}{ Ann Arbor stage } \\
\hline $\mathrm{I}$ & Reference & & Reference & \\
\hline II & $1.54(0.974-2.437)$ & 0,065 & $1.651(0.916-2.976)$ & 0,096 \\
\hline III & $1.644(1.002-2.802)$ & 0,048 & $1.614(0.79-3.297)$ & 0,189 \\
\hline IV & $2.555(1.688-3.867)$ & $<0.001$ & $3.005(1.745-5.173)$ & $<0.001$ \\
\hline \multicolumn{5}{|l|}{ Therapeutic modality } \\
\hline No treatment & Reference & & Reference & \\
\hline Chemotherapy alone & $0.209(0.152-0.288)$ & $<0.001$ & $0.188(0.127-0.279)$ & $<0.001$ \\
\hline Radiation alone & $0.444(0.16-1.233)$ & 0,119 & $0.173(0.023-1.275)$ & 0,085 \\
\hline Combined therapy & $0.187(0.089-0.394)$ & $<0.001$ & $0.201(0.084-0.483)$ & $<0.001$ \\
\hline
\end{tabular}


Table5.Clinical features and immunophenotypical results of 21 patients with plasmablastic lymphoma in our institution

\begin{tabular}{|c|c|c|c|c|c|c|c|c|c|c|c|c|c|c|c|c|c|c|c|c|c|}
\hline \multirow{2}{*}{ Patient } & \multirow{2}{*}{ Gender } & \multirow{2}{*}{$\begin{array}{c}\text { Age } \\
\text { at diagnosis }\end{array}$} & \multirow{2}{*}{$\begin{array}{l}\text { ECOG- } \\
\text { PS }\end{array}$} & \multirow{2}{*}{$\begin{array}{l}\text { Ann-Arbor } \\
\text { Stage }\end{array}$} & \multirow{2}{*}{$\begin{array}{l}\text { IPI } \\
\text { score }\end{array}$} & \multirow{2}{*}{ Localization } & \multicolumn{3}{|c|}{ ISH } & \multicolumn{12}{|c|}{ Immunohistochemistry } \\
\hline & & & & & & & HIV & EBER & $\mathrm{CD} 138$ & CD38 & $\mathrm{CD} 10$ & $\mathrm{CD} 20$ & CD79 & PAX5 & MUM1 & $\mathrm{CD} 30$ & CD56 & BCL6 & CD5 & $\mathrm{CD} 3$ & $\mathrm{CD} 45$ \\
\hline 1 & Male & 17 & 1 & III A & 1 & Small intestine & - & + & + & + & - & - & - & - & + & - & - & ND & ND & - & ND \\
\hline 2 & Female & 37 & 1 & IV B & 2 & Appendix & - & - & + & + & ND & - & - & ND & + & + & - & ND & ND & ND & ND \\
\hline 3 & Male & 77 & 1 & II A & 1 & $\mathrm{LN}$ & - & - & + & + & - & - & - & - & + & - & - & - & ND & ND & - \\
\hline 4 & Male & 28 & 1 & IV A & 2 & LN,spleen,bone marrow & - & - & - & + & - & - & + & + & - & ND & - & - & ND & ND & - \\
\hline 5 & Male & 46 & 1 & IV B & 3 & LN,bone,bone marrow & - & - & + & + & - & + & + & - & + & ND & - & - & + & ND & + \\
\hline 6 & Male & 65 & 1 & IV B & 4 & Oral cavity,bone marrow & - & + & + & + & - & - & + & - & + & ND & + & ND & ND & ND & - \\
\hline 7 & Female & 43 & 1 & IV A & 2 & $\begin{array}{l}\text { LN,nasal sinus and } \\
\text { cavity,mediastinum }\end{array}$ & - & + & + & - & - & - & ND & - & + & ND & + & - & ND & + & - \\
\hline 8 & Female & 57 & 1 & IV A & 1 & $\mathrm{LN}$ & - & - & + & + & & - & - & - & + & - & ND & - & - & - & ND \\
\hline 9 & Female & 53 & 1 & IV A & 2 & $\begin{array}{l}\text { Vagina,liver,right } \\
\text { kidney,pancreas, }\end{array}$ & - & ND & - & & ND & - & - & - & + & - & - & ND & ND & - & - \\
\hline 10 & Female & 51 & 1 & III B & 2 & $\mathrm{LN}$ & - & - & + & + & + & - & - & - & + & + & - & + & ND & - & + \\
\hline 11 & Female & 27 & 1 & IV A & 3 & Stomach,lymph nodes & - & ND & + & + & ND & - & - & ND & + & ND & ND & ND & ND & - & - \\
\hline 12 & Female & 53 & 2 & IV B & 2 & LN, breast & - & ND & + & + & - & - & + & - & + & - & - & ND & ND & - & + \\
\hline 13 & Male & 24 & 3 & IV A & 3 & Vertebral column & - & & + & - & + & - & - & + & - & - & - & ND & ND & - & - \\
\hline 14 & Female & 32 & 0 & IV A & 2 & Stomach & - & ND & + & + & - & - & + & ND & + & ND & - & - & ND & - & ND \\
\hline 15 & Female & 62 & 3 & IV B & 4 & $\begin{array}{l}\text { Right kidney and adrenal } \\
\text { gland,ureter }\end{array}$ & - & - & + & - & - & - & - & - & + & - & - & - & - & - & ND \\
\hline 16 & Male & 52 & 1 & IV A & 1 & Right adrenal gland & - & + & ND & + & - & - & - & - & + & ND & - & ND & ND & - & - \\
\hline 17 & Male & 73 & 1 & I A & 1 & Throat & - & - & + & + & + & - & - & - & + & - & + & ND & ND & - & + \\
\hline 18 & Male & 75 & 3 & II A & 3 & Pleura & - & - & + & + & - & + & - & ND & - & - & - & ND & ND & - & ND \\
\hline 19 & Male & 67 & 1 & IEA & 1 & Stomach & - & - & + & + & ND & - & - & ND & + & ND & + & ND & ND & ND & ND \\
\hline 20 & Male & 45 & 1 & IVA & 1 & LN, gingiva & - & + & + & + & + & - & + & + & + & ND & - & - & & - & - \\
\hline 21 & Male & 60 & 3 & IV B & 5 & LN,kidney & - & - & + & + & ND & - & - & ND & + & + & - & ND & ND & - & ND \\
\hline
\end{tabular}

Abbreviations: ECOG-PS: Eastern cooperative oncology group performance score; LN:Lymph nodes; ISH:In situ hybridization;ND:Not determined 


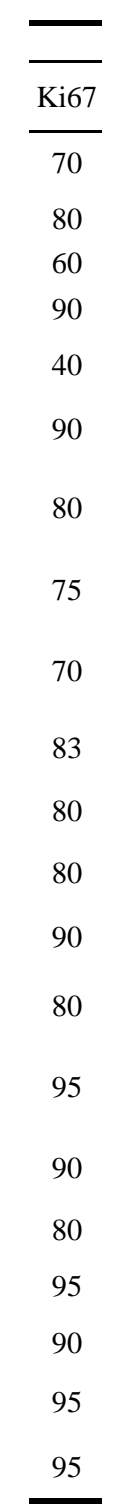

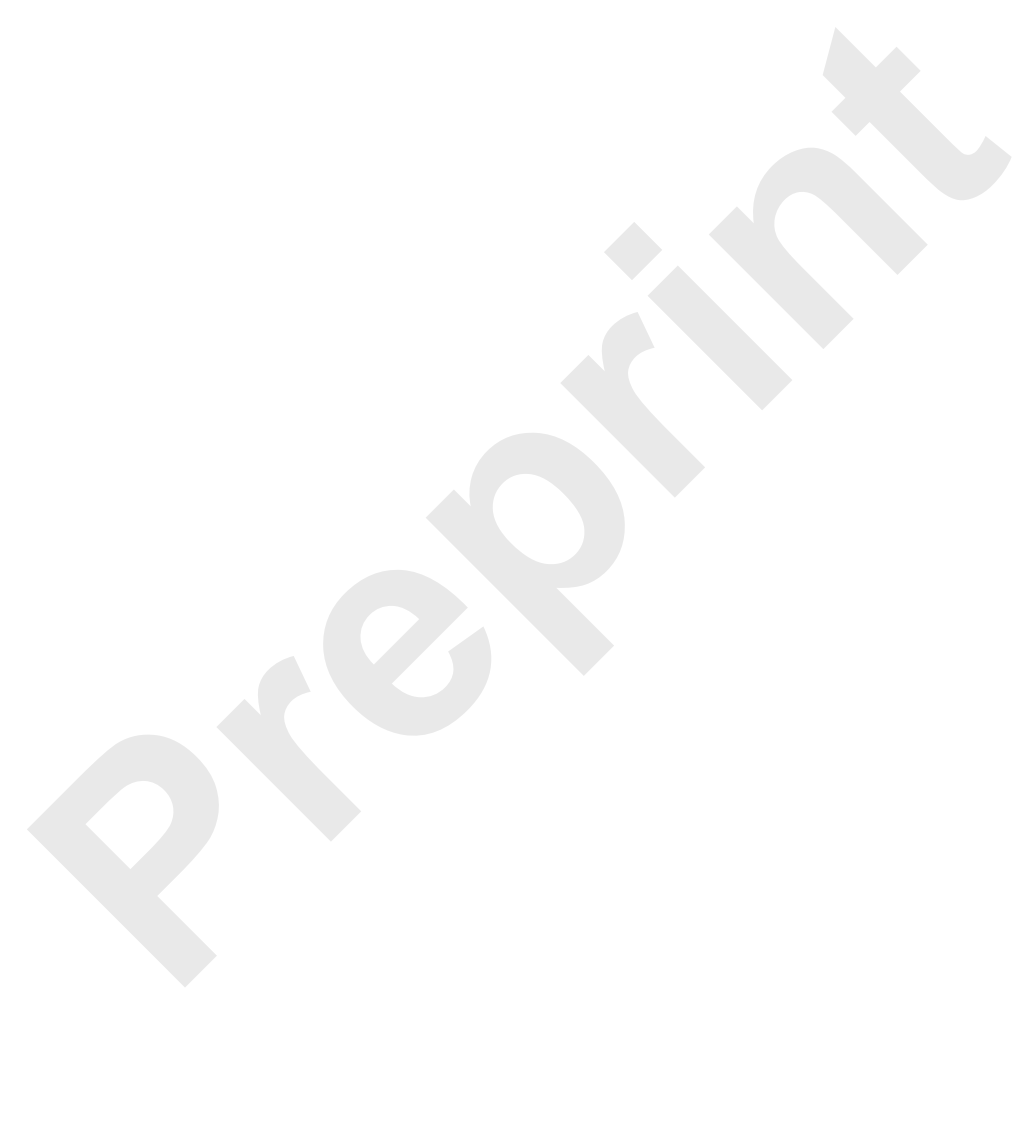


Table6.Therapeutic regimen and survival outcomes of 19 treated patients with plasmablastic lymphoma in our institution

\begin{tabular}{|c|c|c|c|c|c|c|c|}
\hline Patient & Therapeutic regimen & Radiation & Surgery & Best response & Progrssion & Survival(months) & Status at last follow-up \\
\hline 1 & $\mathrm{CAD} \times 2+\mathrm{CHOPE} \times 7$ & - & - & $\mathrm{CR}$ & $\mathrm{CR}$ & 94 & Alive \\
\hline 2 & HOPE $\times 6+\mathrm{PAD} \times 3+\mathrm{ASCT}+\mathrm{TAD}+\mathrm{Thal}$ (maintainanc & - & - & $\mathrm{CR}$ & $\mathrm{CR}$ & 89 & Alive \\
\hline 3 & $\mathrm{CHOPE} \times 8+\mathrm{MINE} \times 1+\mathrm{TAD} \times 1$ & - & - & PR & PD & 41 & Dead of disease \\
\hline 4 & $\mathrm{CHOPE} \times 2+\mathrm{ESHAP} \times 1+\mathrm{VAD} \times 1$ & - & - & PD & PD & 3 & Dead of disease \\
\hline 5 & HyperCVAD×2+CHOP×1 & - & - & PR & PD & 3 & Dead of disease \\
\hline 6 & $\mathrm{CHOP} \times 2+\mathrm{MPT} \times 1$ & - & - & PD & PD & 2 & Dead of disease \\
\hline 7 & $\mathrm{CHOP} \times 2+\mathrm{CHOPE} \times 4$ & - & - & PR & PD & 6 & Dead of disease \\
\hline 8 & $\mathrm{CHOP} \times 1+\mathrm{CHOPE} \times 2+\mathrm{DICE} \times 3$ & - & - & PR & PD & 7 & Dead of disease \\
\hline 9 & CHOPE $\times 6+$ Radiotherapy+MOPE $\times 1$ & + & - & PR & $\mathrm{PD}$ & 10 & Dead of disease \\
\hline 10 & CHOPE $\times 9$ & - & - & PR & PD & 7 & Dead of disease \\
\hline 11 & $\mathrm{CHOP} \times 4+\mathrm{CHOPE} \times 1+\mathrm{ESHAP} \times 3+\mathrm{DHAP} \times 1$ & - & - & PR & PD & 9 & Dead of disease \\
\hline 12 & CHOPE $\times 2$ & - & - & PD & PD & 2 & Dead of disease \\
\hline 13 & $\mathrm{CHOP} \times 2$ & - & - & PD & PD & 2 & Dead of disease \\
\hline 14 & CHOPE $\times 11+$ MOPE $\times 1$ & - & - & PR & PD & 12 & Lost to follow-up \\
\hline 15 & $\mathrm{CVE} \times 1+\mathrm{DA}-\mathrm{EPOCH} \times 2+\mathrm{PAD} \times 1+\mathrm{VCD} \times 1$ & - & - & PD & PD & 5 & Dead of disease \\
\hline 16 & No therapy in our center & NA & NA & NA & NA & NA & Lost to follow-up \\
\hline 17 & No therapy in our center & NA & NA & NA & NA & NA & Lost to follow-up \\
\hline 18 & $\mathrm{CHOPE} \times 3+\mathrm{CHOP} \times 3$ & - & - & PR & $\mathrm{PD}$ & 6 & Dead of disease \\
\hline 19 & $\mathrm{CHOP} \times 8+\mathrm{Thal}($ maintainance $)$ & - & - & $\mathrm{CR}$ & $\mathrm{CR}$ & 50 & Alive \\
\hline 20 & $\mathrm{CDOP} \times 5+\mathrm{CHOPE} \times 3+\mathrm{GDP} \times 1+\mathrm{Thal}($ maintainance $)$ & - & - & PR & PR & 48 & Alive \\
\hline 21 & $\mathrm{CHOP} \times 3$ & - & - & $\mathrm{PD}$ & $\mathrm{PD}$ & 3 & Dead of disease \\
\hline
\end{tabular}

Abbreviations:ASCT: Autologous stem cell transplantation; CAD: Cyclophosphamide+Adriamycin+Dexamethasone; CDOP: Cyclophosphamide+Liposomal

doxorubicin+Vincristine+Prednisone; CHOP: Cyclophosphamide+Adriamycin+Vincristine+Prednisone; CHOPE:

Cyclophosphamide+Adriamycin+Vincristine+Prednisone+Etoposide;CVE: Cyclophosphamide+Vincristine+Etoposide;

DA-EPOCH:Dose-adjusted Etoposide+Adriamycin+Vincristine+Cyclophosphamide+Prednisone;DHAP: Cisplatin+High-dose Cytarabine+Dexamethasone; DICE:

Cisplatin+Ifosfamide+Etoposide+Dexamethasone; ESHAP: Etoposide+Methylprednisolone+High-dose Cytarabine+Cisplatin;

GDP:Gemcitabine+Cisplatin+Dexamethasone; HyperCVAD: Cyclophosphamide+Adriamycin+Vincristine+Dexamethasone; MINE: Mitoxantrone+Ifosfamide+Etoposide;

MOPE: Mitoxantrone+Vincristine+Prednisone+Etoposide; MPT: Melphalan+Prednisone+Thalidomide; PAD: Bortezomib+ Adriamycin+Dexamethasone; PCD:

Bortezomib+Cyclophosphamide+Dexamethasone; TAD: Thalidomide+Adriamycin+Dexamethasone; Thal: Thalidomide;VAD: Vincristine+Adriamycin+Dexamethasone;

CR: complete response; PD: progressive disease; PR: partial response;NA:not available 


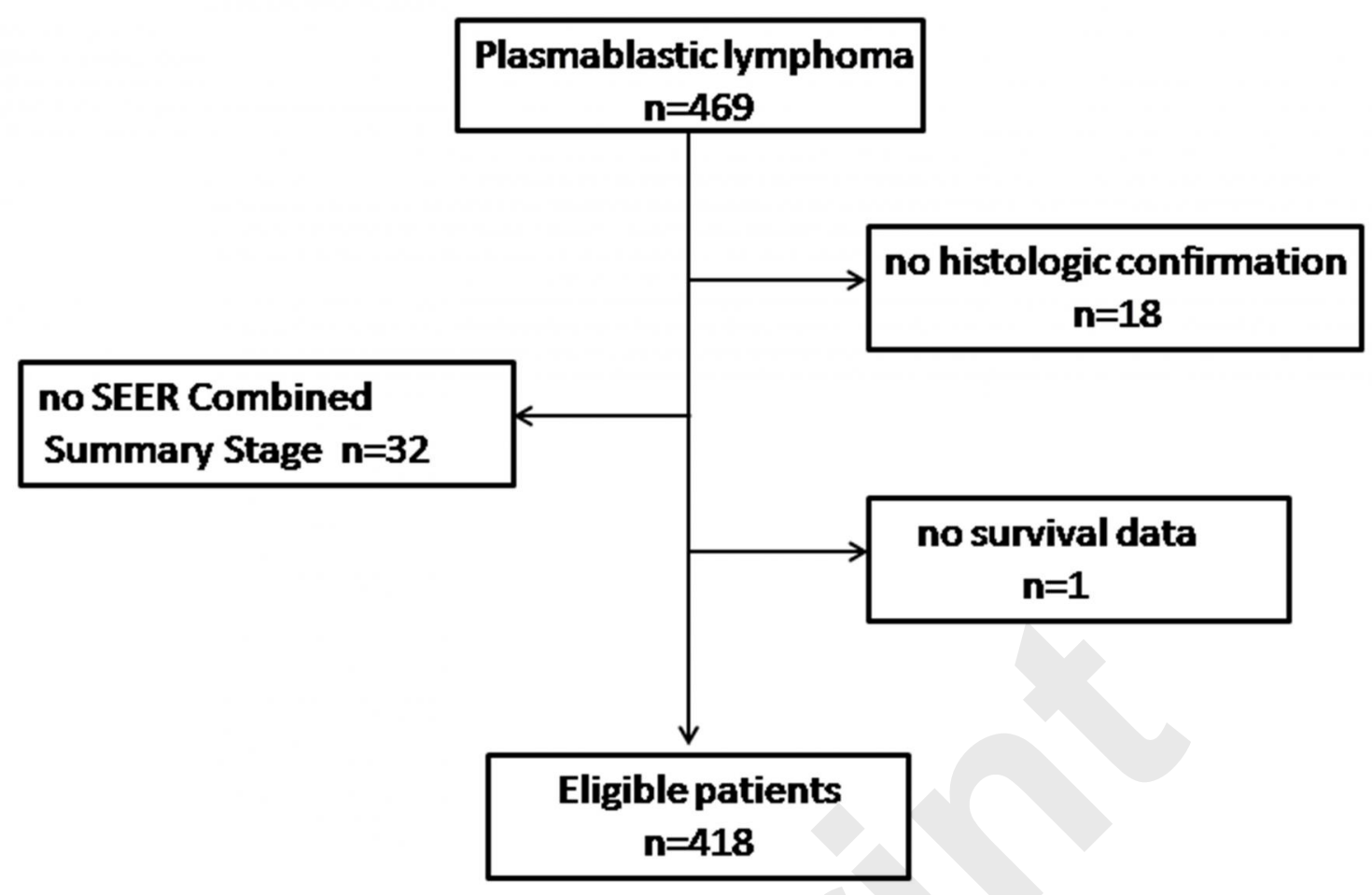

Figure1. The flow chart of the selection process for the eligible patient cohort. 

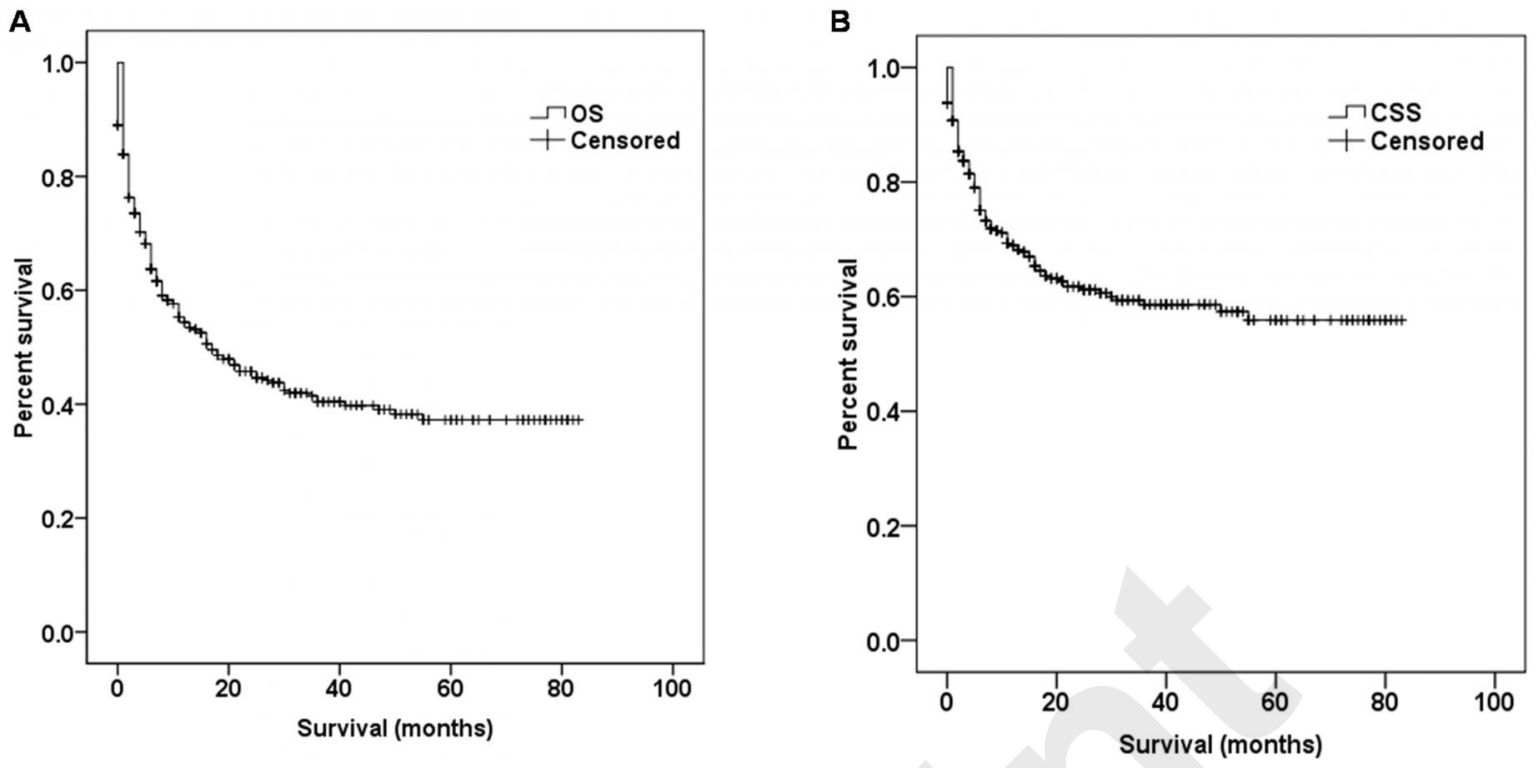

Figure2. Kaplan-Meier curves of the whole eligible cohort: (A) Overall survival; (B) Diseasespecific survival 
A

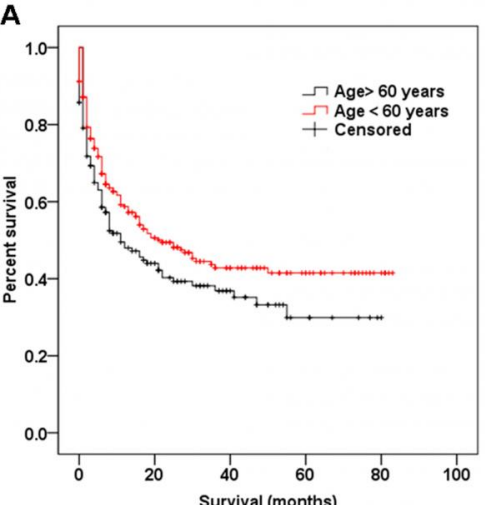

D

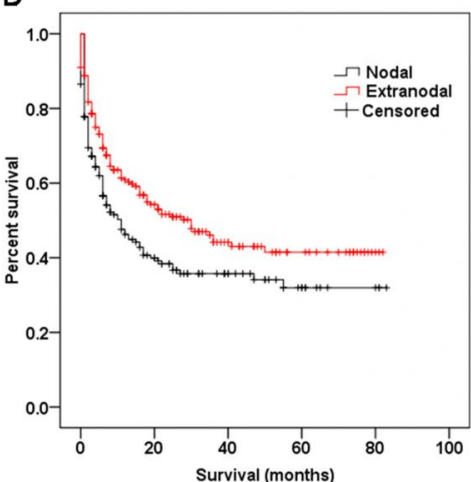

B

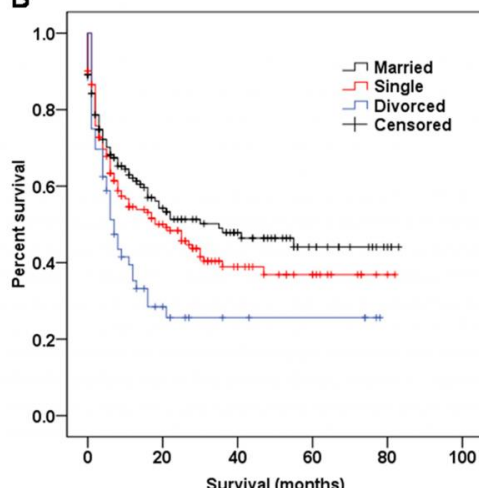

E

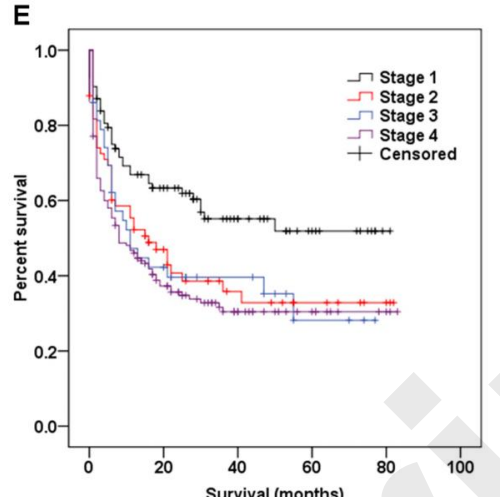

C
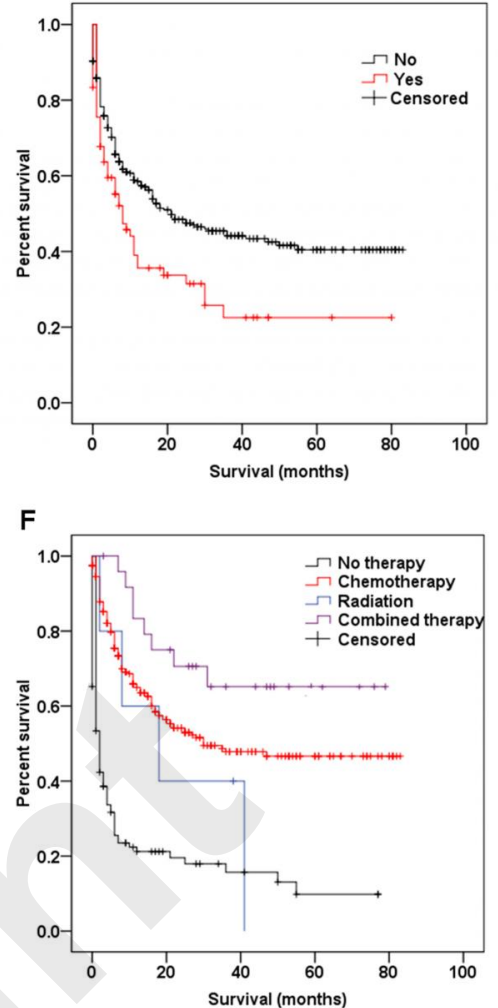

Figure3. Kaplan-Meier estimate of overall survival by subgroup analysis: (A) Age; (B) Marital status; (C) Previous malignancy history; (D) Primary site; (E) Ann Arbor stage; (F)Therapeutic modality. 
A

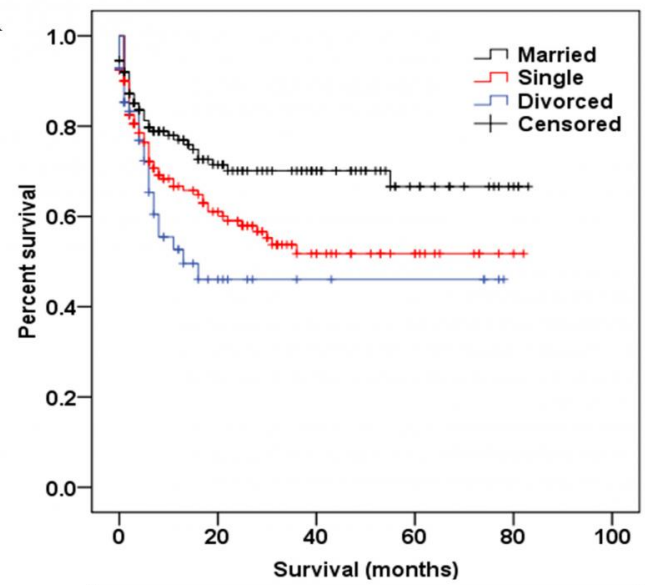

C

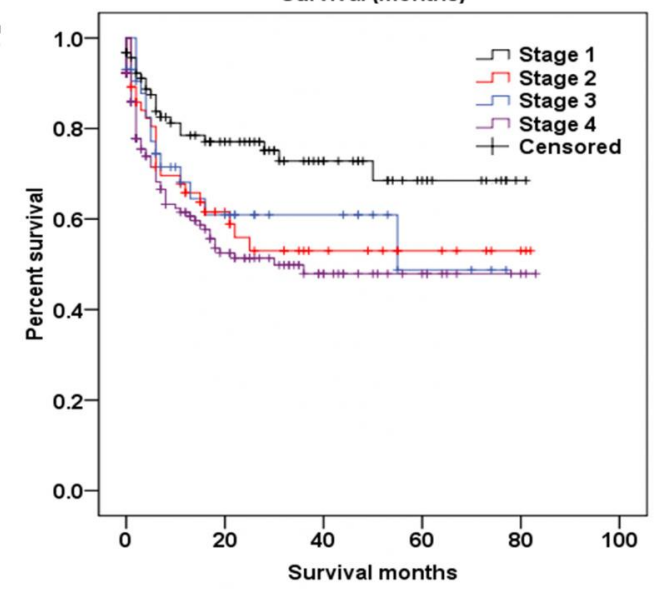

B

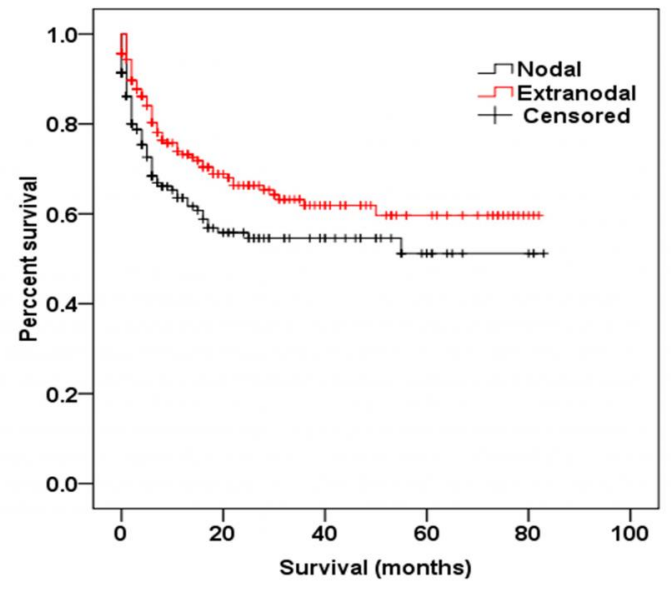

D

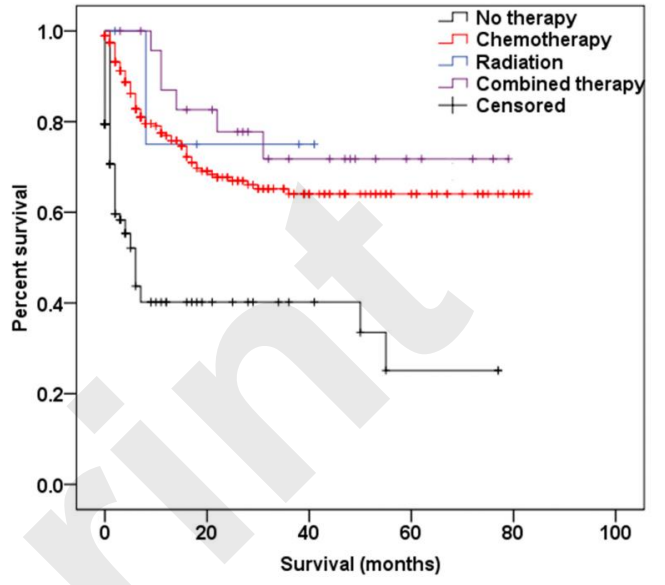

Figure4. Kaplan-Meier estimate of disease-specific survival by subgroup analysis: (A) Marital status; (B)Primary site; (C)Ann Arbor stage;(D)Therapeutic modality. 


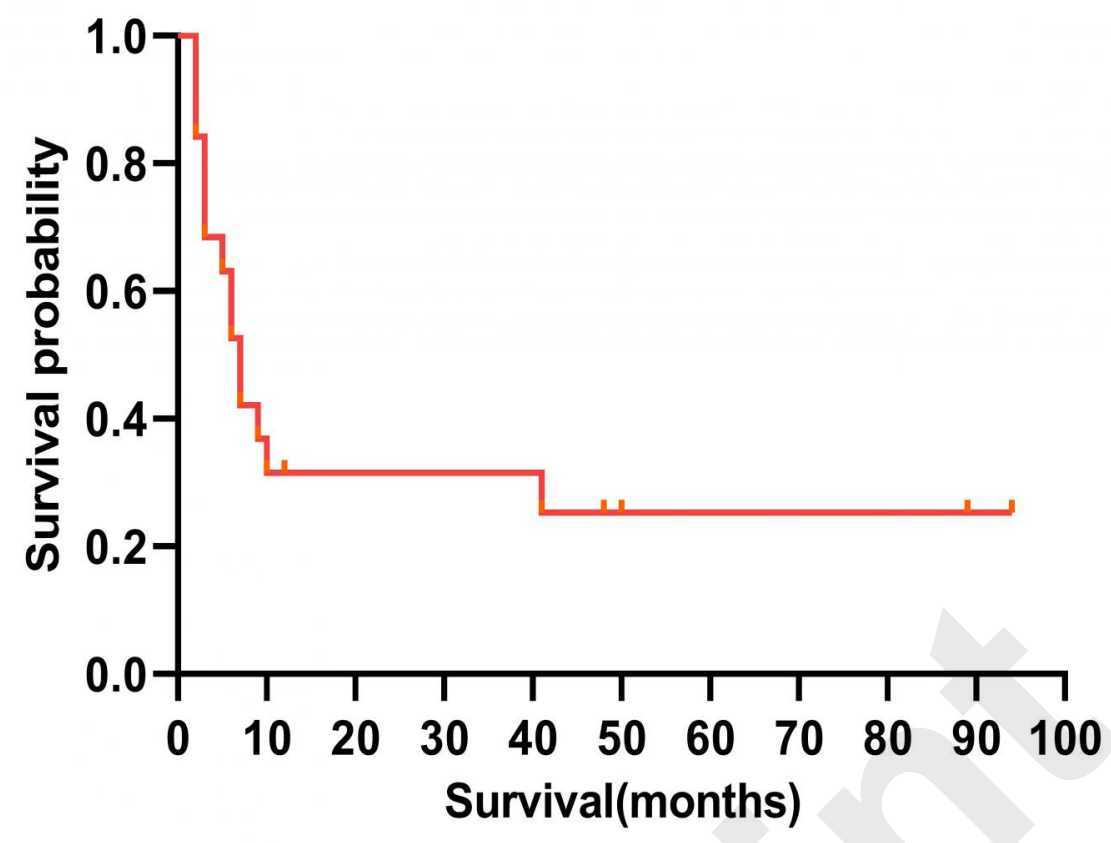

Figure5. Overall survival of 19 plasmablastic lymphoma patients treated in our institution. 